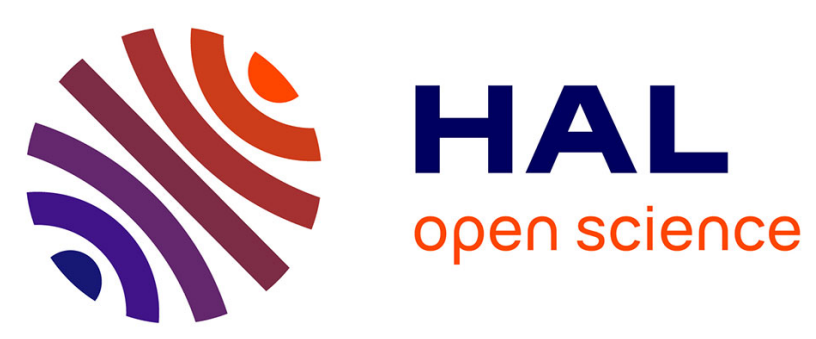

\title{
Correlation of the high and very high cycle fatigue response of ferrite based steels with strain rate-temperature conditions
}

Noushin Torabian, Véronique Favier, Justin Dirrenberger, Frédéric Adamski, Saeed Ziaei-Rad, Nicolas Ranc

\section{To cite this version:}

Noushin Torabian, Véronique Favier, Justin Dirrenberger, Frédéric Adamski, Saeed Ziaei-Rad, et al.. Correlation of the high and very high cycle fatigue response of ferrite based steels with strain rate-temperature conditions. Acta Materialia, 2017, 134, pp.40-52. 10.1016/j.actamat.2017.05.064 . hal-01592775

\section{HAL Id: hal-01592775 \\ https://hal.science/hal-01592775}

Submitted on 25 Sep 2017

HAL is a multi-disciplinary open access archive for the deposit and dissemination of scientific research documents, whether they are published or not. The documents may come from teaching and research institutions in France or abroad, or from public or private research centers.
L'archive ouverte pluridisciplinaire HAL, est destinée au dépôt et à la diffusion de documents scientifiques de niveau recherche, publiés ou non, émanant des établissements d'enseignement et de recherche français ou étrangers, des laboratoires publics ou privés. 
Full length article

\title{
Correlation of the high and very high cycle fatigue response of ferrite based steels with strain rate-temperature conditions
}

\author{
Noushin Torabian a, b, *, Véronique Favier a , Justin Dirrenberger a, Frédéric Adamski a , \\ Saeed Ziaei-Rad ${ }^{\mathrm{b}}$, Nicolas Ranc ${ }^{\mathrm{a}}$ \\ a Laboratoire PIMM, Arts et Métiers Paris Tech, CNAM, CNRS, Paris 75013, France \\ ${ }^{\mathrm{b}}$ Department of Mechanical Engineering, Isfahan University of Technology, Isfahan 84156-83111, Iran
}

\begin{abstract}
A B S T R A C T
The discrepancies observed between conventional and ultrasonic fatigue testing are assessed through the mechanisms of dislocation mobility in BCC metals. The existence of a transition condition between thermally-activated and athermal regimes for screw dislocation mobility is studied under fatigue loading based on infrared thermography and microstructural characterization, here in the case of DP600 dualphase steel. Evidence is obtained regarding the microstructural sources of crack initiation, which is found to be consistent with the existence of a transition in the modes of deformation. From the analysis of the experimental data gathered in this work, guidelines are given regarding the comparison and interpretation of S-N curves obtained from conventional and ultrasonic fatigue testing. The inevitable temperature increases under ultrasonic fatigue at high stress amplitudes along with the rate dependent deformation behavior of ferrite, as a BCC structure, were found as the key parameters explaining the observed fatigue behavior and thermal response under low and ultrasonic frequencies. A transition map was produced using the experimental results for DP600 steel as well as data available in the literature for other ferrite based steels, showing the correlation between thermally-activated screw dislocation movement and the absence of failure in very high cycle fatigue.
\end{abstract}

\section{Introduction}

The increased demand for material fatigue characterization in gigacycle regimes has provoked further use and development of ultrasonic fatigue testing systems. Owing to a high frequency of usually $20 \mathrm{kHz}$, this loading technique allows to reach very high number of cycles up to $\mathrm{N}=10^{9}$ in a reasonable time and at lower costs compared to conventional low frequency loadings. However, this accelerated testing method has been always accompanied by a main question: are the fatigue properties obtained from ultrasonic loading similar to those measured by conventional low frequency testing? The answer has remained unclear for most metallic materials [1] and thus the so-called "frequency effect" has been controversial among researchers [2].

Generally, the influence of frequency stems from two main sources: strain rate effects and time dependent influence of

\footnotetext{
* Corresponding author. Laboratoire PIMM, Arts et Métiers Paris Tech, CNAM, CNRS, Paris 75013, France.

E-mail address: noushin.torabiandehkordi@ensam.eu (N. Torabian).
}

environment. The former is the case for high ductility and strain rate sensitive materials such as low-carbon steels while the latter has been reported for some FCC materials such as aluminum alloys [2-5]. Low- and medium-carbon ferritic steels exhibit clear discrepancy between fatigue life and fatigue strength, obtained from ultrasonic loading and those measured from conventional fatigue tests [2]. In this case, as a general trend, ultrasonic loadings produce higher fatigue lives than low frequency tests. The elevated fatigue life and fatigue limit under ultrasonic loading has been mostly attributed to the increase of yield strength due to increasing the strain rate $[2,4,6-10]$. Tsutsumi et al. [6] reported that the longer fatigue life and the higher fatigue limit of low-carbon steels under ultrasonic fatigue are due to a reduction in crack tip cyclic plasticity and subsequent lower crack growth rate during ultrasonic loading. A surface-to-internal-crack initiation transition has been reported by Furuya et al. [11] as the cause of longer fatigue life of ultrafine-grain steel under ultrasonic fatigue testing.

Guennec et al. [10] attributed the higher fatigue life and fatigue strength of low-carbon steel, under ultrasonic loading to transition of crack initiation mode from the usual transgranular, often 
reported at lower loading frequencies, to intergranular crack initiation at ultrasonic frequencies. They $[9,10]$ showed that under usual frequencies of $0.2-140 \mathrm{~Hz}$, dislocation dipoles as ladder or cell structures are induced whereas in the case of $20-\mathrm{kHz}$ ultrasonic loading, long segments of screw dislocations are produced. These results revealed the fact that the screw dislocations were nearly immobile during the conducted ultrasonic tests.

The effect of frequency on fatigue properties of low- and mediumcarbon steels results from a particular behavior of BCC structure of ferrite grains contained in these steels. In BCC metals, the flow stress depends strongly on temperature and strain rate at low temperatures. It was first proposed by Seeger [12] that for BCC metals the flow stress, $\sigma$, can be separated into an athermal component $\sigma_{G}$, and a thermal or effective component $\sigma^{*}$, as $\sigma=\sigma_{G}+\sigma^{*}(\dot{\varepsilon}, T)$. The athermal component is the stress that a gliding dislocation requires to overcome the long range elastic interaction with other dislocations. The thermal or effective component is the stress required for screw dislocations to overcome short obstacles by thermally-activated mechanisms. This thermal component depends on temperature $T$, and strain rate $\dot{\varepsilon}$ and becomes negligible above a transition temperature, $T_{0}$ (or below a transition strain rate, $\dot{\varepsilon}_{0}$ ). For cyclic loading, Mughrabi et al. [13] defined two deformation regimes based on the transition temperature: (1) the thermally-activated mode $\left(T<T_{0}\right)$ where the screw dislocations are immobile and edge dislocations move to-andfro in a non-hardening quasi-recoverable manner (2) the athermal regime $\left(T>T_{0}\right)$ where the mobilities of screw and edge dislocations are equivalent and screw dislocations can cross slip. In this regime, rearrangement of dislocations can take place and strain localization can occur in slip bands. The transition temperature $T_{0}$ is highly strain rate dependent and can be shifted to higher values by increasing the strain rate. Therefore, the thermally-activated regime can be reached at high temperatures providing that the strain rate is sufficiently high.

On the contrary to low and medium strength steels, high alloy and high strength steels (e.g. martensitic stainless steels) are less susceptible to frequency effects and often there is a good agreement between their fatigue life obtained from ultrasonic loadings and that measured from low frequency fatigue tests [14-18]. According to Mayer [2], why the fatigue properties of high strength steels are not sensitive to the loading frequency is due to the very small plastic strain rate involved in high-cycle-fatigue (HCF) and very-high-cycle fatigue (VHCF) loadings of these materials.

As mentioned previously, strain rate and environmental effects are considered as the main causes of frequency effects in ultrasonic fatigue loading. Because of the high frequency, significant temperature rises can occur under ultrasonic fatigue loading of metals especially at high stress amplitudes [19]. Thus, temperature can be considered as a third cause of frequency effect in ultrasonic testing $[4,6]$. Since heating can usually be avoided by cooling the specimen during the test or by employing intermittent loadings, temperature has not been commonly considered as an effective factor on material fatigue response but is recognized as a rather fictitious effect which should be excluded by effective cooling or measuring by pulse-pause testing. However, the effect of heat generation cannot be impeded for all materials under ultrasonic fatigue loading even by cooling the specimen and using a pulse-pause mode [20-22]. The presence of inevitable heating effects under ultrasonic tests at high stress amplitudes has been already confirmed in a previous work of the authors for ferritic-martensitic steel [23]. Peng et al. [21] stated that for structural steels with low tensile strength the specimen is prone to heating and burning at high stress amplitudes even by employing intermittent loading along with cooling systems. Yu et al. [20] affirmed that for bainite-martensite steels under intermittent ultrasonic loading, when the stress level is high, the generated heat cannot be dissipated effectively in spite of maximizing the interruption time and minimizing the oscillation time.
Ranc et al. [24] reported strong temperature increase up to few hundreds of degrees for C45 steel under ultrasonic loading, in spite of using cooling systems.

In a variety of research works on fatigue loading on BCC materials, the temperature increase has been reported to be less than $100{ }^{\circ} \mathrm{C}$, therefore the effect of temperature increase on the fatigue and deformation of the material has not been studied (see for example [4,10,24-26]). However, concerning the temperature dependent flow behavior of BCC structures, even these limited amounts of temperature increase should be taken into account. Moreover, studies involving ultrasonic frequency effects were mainly focused on the effect of frequency on fatigue lifetime, fatigue strength, crack initiation mechanisms, crack growth rate, and dislocation mechanisms. In spite of the importance of temperature on fatigue response of BCC materials, there is a lack of investigation about the mechanisms behind the temperature increase under fatigue loading and the influences which it imposes on fatigue behavior of the material.

The present work aims at explaining the high and very high cycle fatigue behavior of BCC structures accounting for strain rate and temperature effects. DP600 dual-phase steel which consists of a ferrite matrix containing martensite islands was investigated under $20-\mathrm{kHz}$ ultrasonic loading as well as conventional low frequency fatigue tests. In both cases, the S-N curves were obtained and the effect of frequency on fatigue life and fatigue limit was studied. Fractography studies were conducted and effect of frequency on crack initiation and material failure was investigated. Moreover, thermographic measurements were performed and mechanisms were proposed to explain the observed abnormal thermal response of the material under ultrasonic loading and correlate it to the fatigue and deformation behavior. A strain ratetemperature transition map was developed to correlate the fatigue response of the material to deformation mechanisms by gathering the results of the present paper and data from literature for ferrite based steels.

\section{Material and experiments}

The material studied in this research was a commercial DP600 dual-phase steel. This ferritic-martensitic steel which contains $15 \mathrm{wt} \%$ martensite was received as sheets of $3.6 \mathrm{~mm}$ thickness from ArcelorMittal. The chemical composition and the mechanical properties of the material are presented in Tables 1 and 2, respectively. Ultrasonic and conventional low frequency fatigue tests were carried out by using a piezoelectric $20-\mathrm{kHz}$ system and a $10-$ $\mathrm{kN}$ servo-hydraulic MTS machine, respectively. All fatigue tests were performed under fully reversed tension-compression conditions $(R=-1)$. Hourglass-shaped specimens with rectangular cross section were used with the geometries shown in Fig. 1. The dimensions of ultrasonic fatigue samples were obtained by solving the vibration equations in order to reach a resonant vibration frequency of $20 \mathrm{kHz}$ for the specimen. The conventional fatigue specimens were designed so that for the same displacement amplitude, the stress distribution in the neighborhood of the specimen center is equivalent to that of ultrasonic specimen [27]. Ultrasonic fatigue tests are displacement-controlled while conventional fatigue loadings are performed under load-controlled conditions. In both cases loading amplitude was low so that the

Table 1

DP600 chemical composition [28].

\begin{tabular}{llllllll}
\hline Alloying element & $\mathrm{Mn}$ & $\mathrm{Ni}$ & $\mathrm{Si}$ & $\mathrm{Cr}$ & $\mathrm{C}$ & $\mathrm{Al}$ & $\mathrm{Nb}$ \\
\% weight & 0.933 & 0.020 & 0.213 & 0.727 & 0.0748 & 0.039 & 0.0425 \\
\hline
\end{tabular}


Table 2

Mechanical properties of DP600 steel [28].

\begin{tabular}{|c|c|c|c|}
\hline Young's Modulus (GPa) & Yield strength (MPa) & Ultimate tensile strength (MPa) & Elongation (\%) \\
\hline 210 & 440 & 650 & 20 \\
\hline
\end{tabular}

specimen deformed elastically from the macroscopic viewpoint. Therefore the difference in loading conditions does not have a strong impact on the results $[2,4]$. All specimens were electropolished after mechanical polishing in order to remove any induced residual stresses and to minimize the size effects [9]. In the case of ultrasonic tests a continuous loading technique was employed (pulse-pause mode was not used) and an air-cooling system was used to cool down the specimen. Moreover, in situ infrared thermography was employed to record the mean temperature on the specimen surface under fatigue loadings. In all cases the temperature was measured at the center of the gauge part of the specimen in a circular area with a diameter of $\sim 1 \mathrm{~mm}$. The details of temperature measurement method can be found in Ref. [23].

\section{Experimental results}

\section{1. $S$ - $N$ curves}

The S-N curves were obtained by $20-\mathrm{kHz}$ ultrasonic loadings along with cooling the specimen with compressed air, and also by $30-\mathrm{Hz}$ conventional fatigue tests. The obtained S-N data is presented in Fig. 2. It can be seen that for a given stress amplitude $\sigma_{a}$, the fatigue lifetime measured by ultrasonic loading was higher than that obtained from conventional tests. The number of cycles at the knee point obtained at $30 \mathrm{~Hz}$ was $\sim 2 \times 10^{6}$ cycles, whereas the corresponding value at $20 \mathrm{kHz}$ was $\sim 3 \times 10^{8}$ cycles. For a given

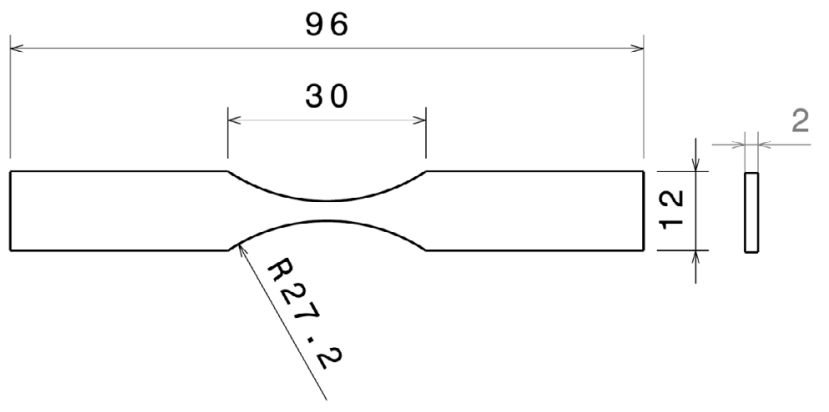

(a)

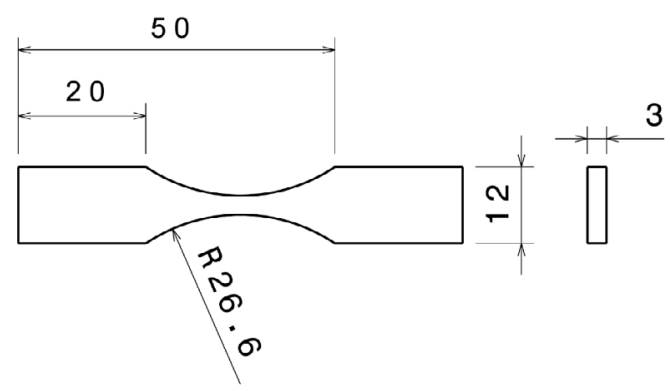

(b)

Fig. 1. (a) Ultrasonic fatigue specimen (b) Conventional fatigue specimen (dimensions are in $\mathrm{mm})$. number of cycles ranging from $10^{6}$ to $10^{7}$, where the data exists for both loading techniques, the fatigue strength is higher at $20 \mathrm{kHz}$ than at $30 \mathrm{~Hz}$. However, both frequencies have resulted in the same fatigue limit of $\sigma_{D}=260 \pm 5 \mathrm{MPa}$.

Based on infrared thermography measurements, in the case of ultrasonic loadings at stress amplitudes above the fatigue limit (all points in the S-N diagram excluding the run-out points), strong heating occurred in the early stages of cycling, leading to significant temperature increases up to $350^{\circ} \mathrm{C}$. However, at stress amplitudes below the fatigue limit, the temperature remained below $40^{\circ} \mathrm{C}$. The high temperature increases at high stress amplitudes could not be avoided even by using air-cooling systems. In the case of $30-\mathrm{Hz}$ frequency, temperature increase was negligible $\left(\Delta \mathrm{T}<15{ }^{\circ} \mathrm{C}\right)$ in comparison with ultrasonic loadings and no cooling system was required.

\subsection{Fractography studies}

Fracture surfaces of all conventional and ultrasonic ruptured specimens were investigated by Scanning Electron Microscopy (SEM) and representative results are presented in Figs. 3 and 4 for some of the samples. For all specimens ruptured under $30-\mathrm{Hz}$ frequency loading, the macroscopic fatigue crack initiated from the specimen surface. In this case, both single and multiple crack initiation sites were detected, as shown by yellow arrows in Fig. 3. The ductile relief of the surface without any trace of grain boundaries suggests the occurrence of transgranular crack propagation. This observation is consistent with the observations of microcracks within some slip bands at the surface of the specimen (see Section 3.3.).

Fig. 4 shows the fractography results for the $20-\mathrm{kHz}$ loading. Under ultrasonic fatigue tests, the crack initiation leading to the macroscopic failure was mainly internal however some cases of surface crack initiation were also observed. In this case, crack initiation was always inclusion-induced for both internal and surface crack initiations. For instance, Fig. 4(a) shows an inclusioninduced surface initiation sample for a specimen ruptured at $\mathrm{N}=6 \times 10^{6}$ cycles at stress amplitude of $286 \mathrm{MPa}$. Fig. 4(b) shows the higher magnification of Fig. 4(a), in which inclusions can be seen on the specimen surface, as the cause of surface crack initiation. An internal inclusion-induced crack initiation leading to fisheye fracture after $\mathrm{N}=6.1 \times 10^{7}$ cycles at $\sigma_{a}=275 \mathrm{MPa}$ is presented in Fig. 4(c). A higher magnification of this image showing the inclusion in the center of the fish-eye is depicted in Fig. 4(d). In most cases, non-metallic inclusions such as $\mathrm{Al}_{2} \mathrm{O}_{3}, \mathrm{SiO}_{2}, \mathrm{MgO}$, and $\mathrm{CaO}$ or sulfides are observed in the center of fish-eyes for structural metallic materials $[16,29,30]$. In our case, energy-dispersive spectroscopy (EDS) analysis revealed that the inclusions consist mainly of aluminum, magnesium and oxygen. Fig. 4(d) shows that particlematrix debonding has occurred which can be a part of fatigue crack formation [30].

\subsection{Surface observations}

Interrupted fatigue tests were conducted and the surface of the specimens was observed by SEM at different loading stages. All observations were made along the central axis of the specimen around the center of the gauge part. Fig. 5 shows the SEM 


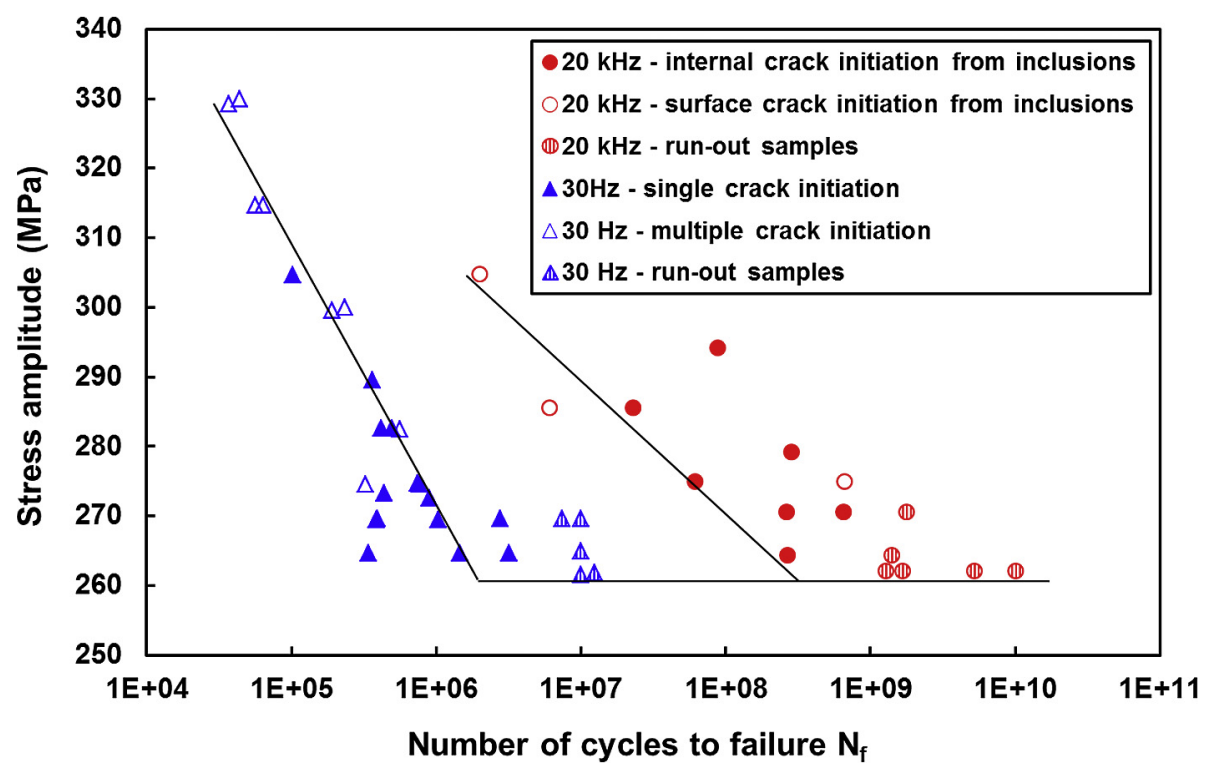

Fig. 2. S-N data of DP600 steel, obtained from $20-\mathrm{kHz}$ and $30-\mathrm{Hz}$ fatigue loadings.

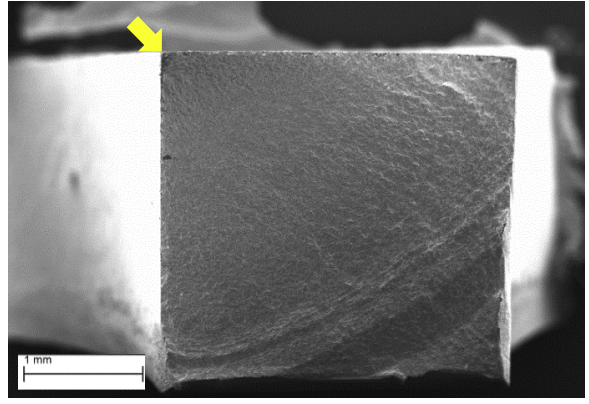

(a)

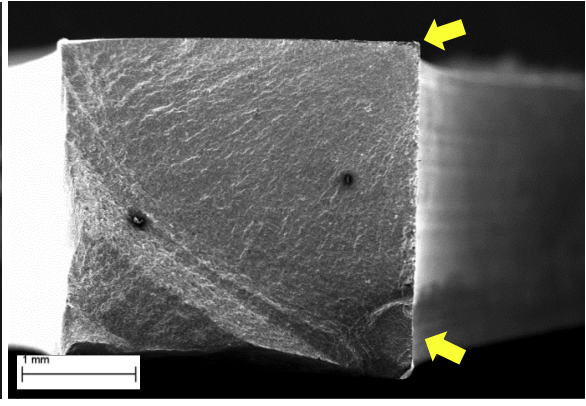

(b)

Fig. 3. Fracture surface of the low frequency specimen ruptured at (a) $\sigma_{a}=270 \mathrm{MPa}$ and $\mathrm{N}_{\mathrm{f}}=1 \times 10^{6}$ cycles (b) $\sigma_{a}=300 \mathrm{MPa}$ and $\mathrm{N}_{\mathrm{f}}=2.3 \times 10^{5}$ cycles.

micrograph of a specimen loaded by $20-\mathrm{kHz}$ frequency at stress amplitude of $\sigma_{a}=260 \mathrm{MPa}$, corresponding to the obtained fatigue limit, after $\mathrm{N}=1.6 \times 10^{9}$ cycles. The specimen was cooled during the test by an air-cooling system and the mean temperature was below $40{ }^{\circ} \mathrm{C}$. The same observations were carried out for a specimen loaded by $30-\mathrm{Hz}$ frequency at $\sigma_{a}=250 \mathrm{MPa}$, below the fatigue limit, after $\mathrm{N}=2 \times 10^{5}$ cycles and $\mathrm{N}=10^{7}$ cycles and the results are presented in Fig. 6. In Fig. 5 the dark phase is ferrite and the bright phase is martensite. Since in the case of conventional $30-\mathrm{Hz}$ frequency the experiment was long, the specimen surface was not so clean after loading. This is why the contrast in Fig. 6 is different from Fig. 5 and ferrite and martensite phases cannot be easily distinguished especially in Fig. 6 (b). In the case of ultrasonic loading no slip band (SB) was observed on the specimen surface even after $10^{9}$ cycles. On the other hand, for $30-\mathrm{Hz}$ conventional loading, SBs formed in ferrite grains on the specimen surface in the early stages of loading ( $\mathrm{N} \sim 10^{5}$ cycles) and were developed by increasing the number of cycles. The slip bands are indicated by arrows in the micrographs. For ultrasonic loadings at stress amplitudes above the fatigue limit, which were accompanied by high temperature increases $\left(\sim 350^{\circ} \mathrm{C}\right)$, SEM observations of the specimen surface revealed formation of many slip bands as well as microvoids and microcracks along the slip bands in ferrite grains, as shown in Fig. 7.
Moreover, observations were made on the surface of ruptured specimens, in regions $\sim 900 \mu \mathrm{m}$ away from the final crack. Fig. 8 shows the surface of two specimens ruptured under ultrasonic loading at different loading conditions. As shown in Fig. 8(a), many micro-voids can be observed on the specimen surface. The microvoids form and coalesce along the slip bands inside ferrite grains. No void was observed in grain boundaries and the voids preferentially formed in ferrite grains surrounded by several martensite islands. Fig. 8(b) shows microcracks resulted from void coalescence along the slip bands in ferrite grains for another ultrasonic specimen. The observations results for specimens ruptured under conventional fatigue tests were different as shown in Fig. 9. A lot of slip bands can be observed as bright lines in ferrite grains, however, no void was detected, in contrary to the ultrasonic case. Microcracks are formed along the slip bands in some ferrite grains as shown in Fig. 9 (b) for a specimen ruptured at $\mathrm{N}_{\mathrm{f}}=8.9 \times 10^{5}$ cycles and $\sigma_{a}=272 \mathrm{MPa}$. This fracture mode is consistent with the wellaccepted model for the crack initiation in the conventional fatigue regime $\left(\mathrm{N}<10^{7}\right.$ cycles), where the propagative fatigue cracks leading the specimen to the final fracture are caused by the persistent slip bands on specimen surface [29,31]. In both, ultrasonic and low frequency loading results, all observed cracks formed and propagated in a transgranular manner, no intergranular fracture was detected. 


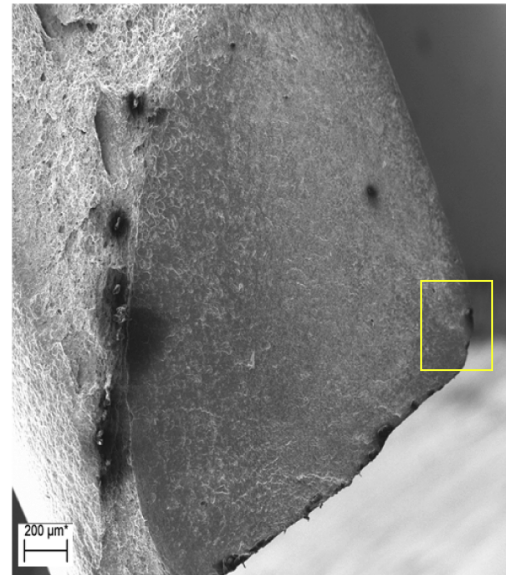

(a)

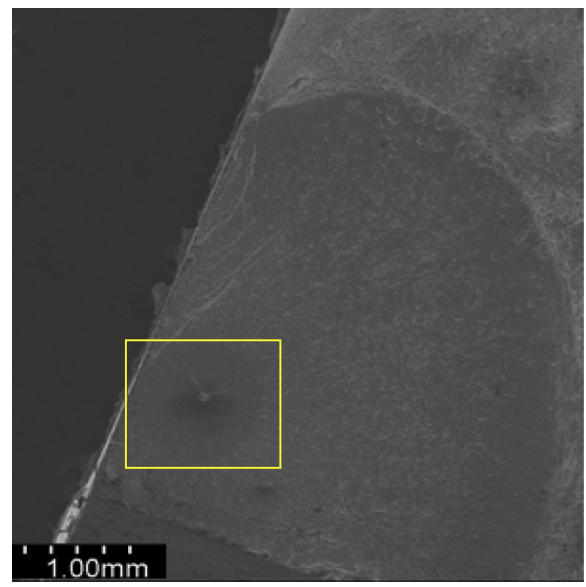

(c)

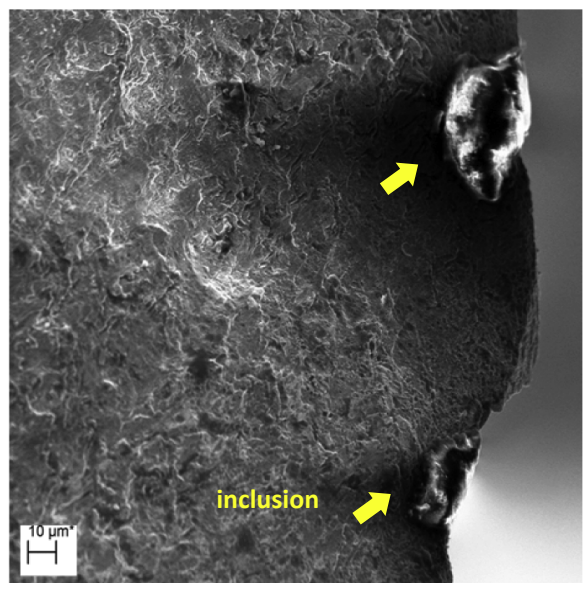

(b)

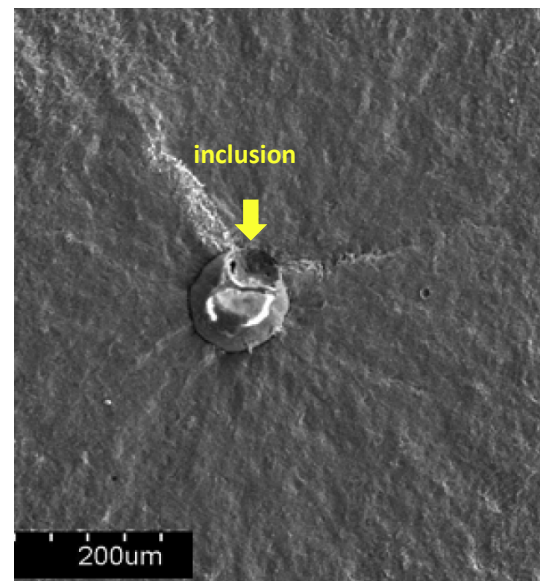

(d)

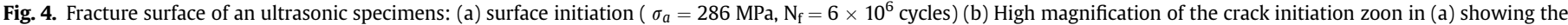
inclusion (c) Fish-eye fracture ( $\sigma_{a}=275 \mathrm{MPa} \mathrm{N}_{\mathrm{f}}=6.1 \times 10^{7}$ cycles) (d) High magnification of (c) showing the inclusion in the center of fish-eye.

\section{Discussion}

The experimental observations presented in Section 3 revealed some possible influences of the ultrasonic frequency on different

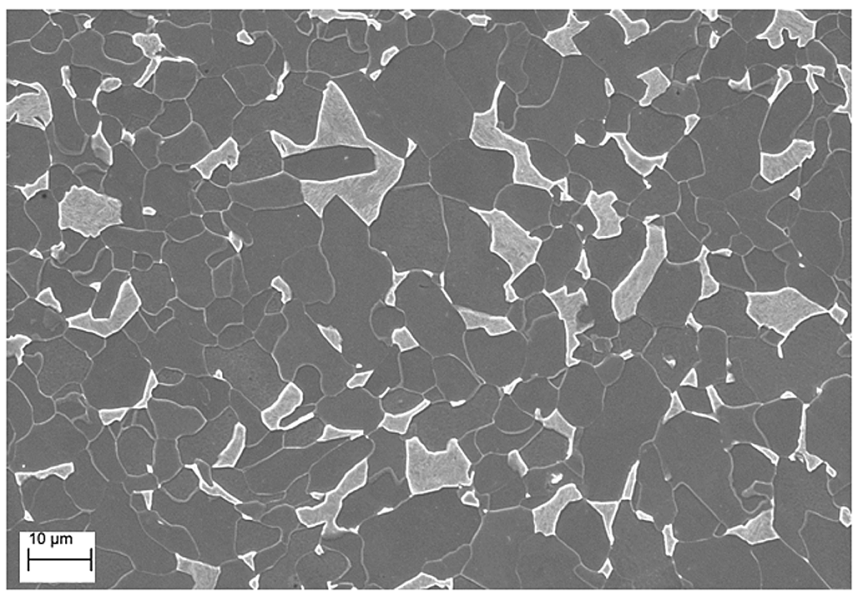

Fig. 5. Surface of the specimen loaded under $20-\mathrm{kHz}$ frequency at $\sigma_{a}=260 \mathrm{MPa}$, $\mathrm{N}=1.6 \times 10^{9}$ cycles, $\mathrm{T}<40^{\circ} \mathrm{C}$. aspects of the fatigue response of the dual-phase steel, including fatigue life, as well as deformation and fracture mechanisms. In this section, complementary discussions are developed on potential phenomena involved in ultrasonic frequency effect on fatigue and thermal responses of the ferritic-martensitic dual-phase steel.

\subsection{Effect of frequency on deformation mechanisms}

In dual-phase steel, since the hardness of martensite is much higher than ferrite, it can be assumed that dislocation motions and plastic deformation occur in ferrite grains, as the ductile phase with a BCC structure. As mentioned earlier, the frequency effect on fatigue behavior of BCC metals results from strain rate sensitivity of these materials, based on which material deformation can occur in thermally-activated or athermal regime. For pure iron the transition strain rate between these two regimes at room temperature is $\sim 10^{-4} s^{-1}$ [13]. However, in low-carbon steel, the presence of solute atoms and precipitates inside ferrite phase decreases the discrepancies between screw and edge dislocations mobilities and consequently results in increasing the transition strain rate at the same temperature or equally decreasing the transition temperature $T_{0}$ at constant strain rate $[10,13]$. Recently, Guennec et al. [10] reported that the transition strain rate of low-carbon steel should lie in the range of $1 \mathrm{~s}^{-1}$ to $10 \mathrm{~s}^{-1}$. Using experimental data for several low carbon steels, in 1966, Rosenfield and Hahn [32] suggested an 


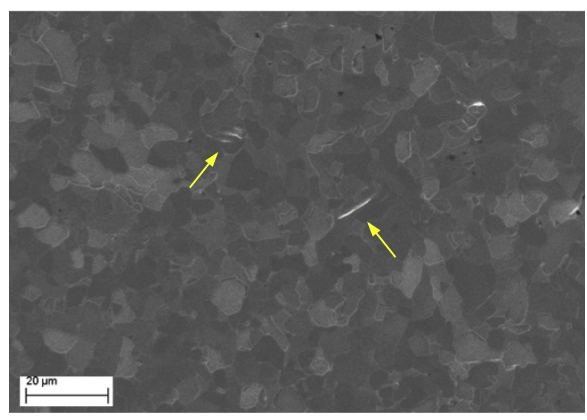

(a)

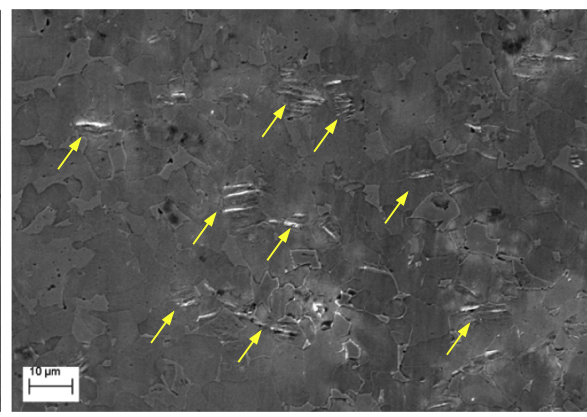

(b)

Fig. 6. Appearance of slip bands in ferrite grains on the surface of the specimen under $30-\mathrm{Hz}$ fatigue loading at $\sigma_{a}=250 \mathrm{MPa}$ after (a) $\mathrm{N}=2 \times 10^{5}$ cycles (b) $\mathrm{N}=10^{7}$ cycles, $\Delta \mathrm{T}<15^{\circ} \mathrm{C}$.

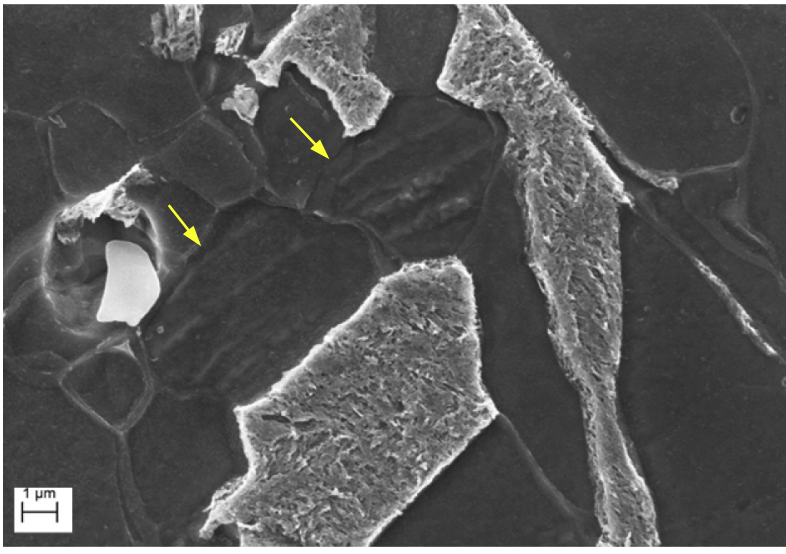

(a)

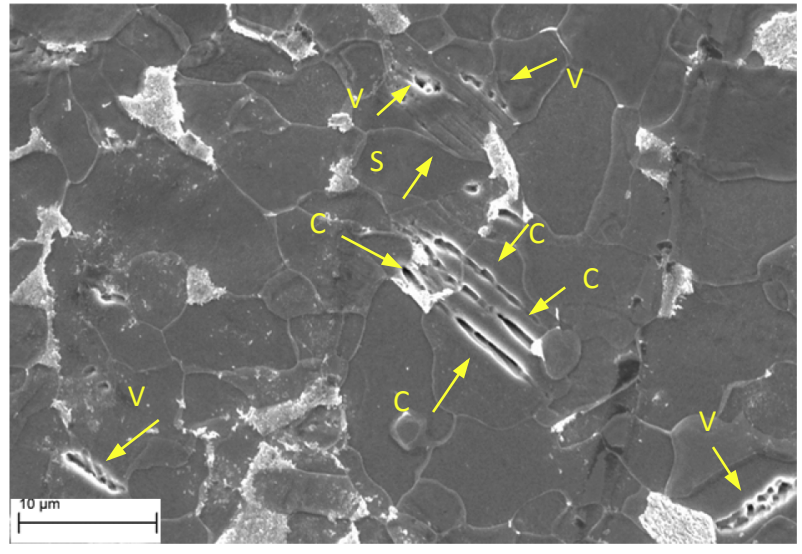

(b)

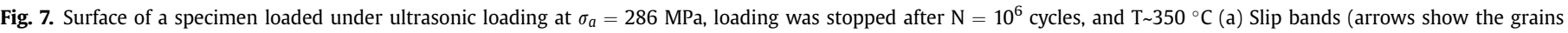
containing the slip bands) (b) microvoids and microcracks (S: slip bands, V: microvoids, and C: microcracks).

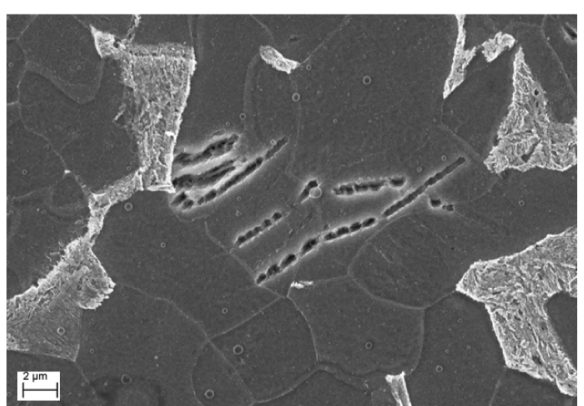

(a)

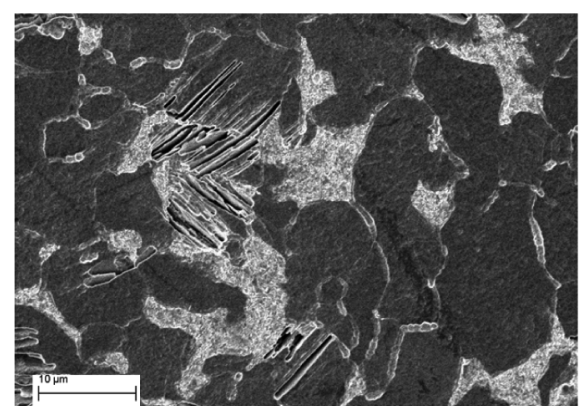

(b)

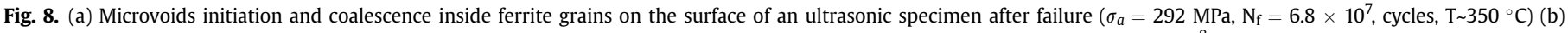
Microcracks along the slip bands in ferrite grains on the surface of an ultrasonic specimen after failure $\left(\sigma_{a}=280 \mathrm{MPa}, \mathrm{N}_{\mathrm{f}}=2.86 \times 10^{8} \mathrm{cycles}, \mathrm{T} \sim 350{ }^{\circ} \mathrm{C}\right)$.

empirical equation representing the transition between athermal regime and thermally-activated regime for low carbon steels as follows:

$\log (\dot{\varepsilon})=1.39 \sqrt{T}-23.7$

where $\dot{\varepsilon}$ is the strain rate and $T$ is temperature in Kelvin. Note that here the mentioned strain rate is the total strain rate whereas it should be the plastic strain rate as plastic deformation mechanisms are concerned. In fatigue, since plastic deformation mechanisms are localized in slip bands, it is difficult to estimate the overall plastic strain rate. That is why in the following, we considered the total strain rate as commonly considered in the literature for fatigue analyses.

In the present work, for conventional $30-\mathrm{Hz}$ frequency fatigue tests with the stress amplitudes in the range of 260-330 MPa (as shown on Fig. 2) the maximum strain rate was estimated to range from $0.233 s^{-1}$ to $0.296 s^{-1}$, considering elastic macroscopic 


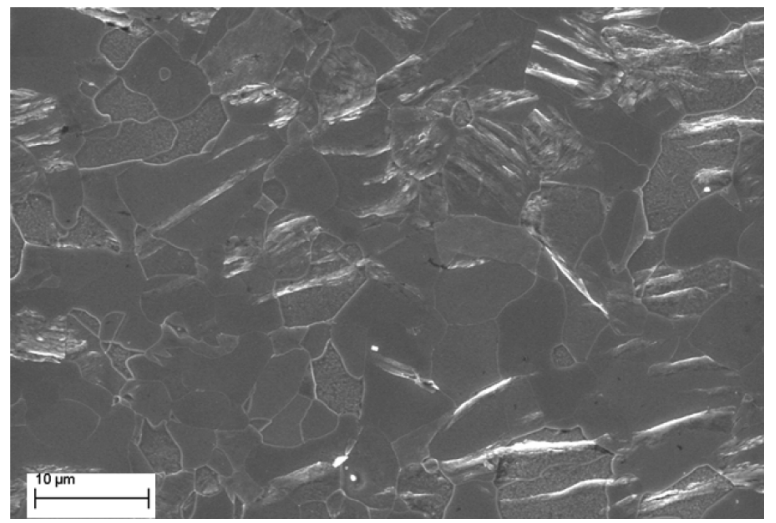

(a)

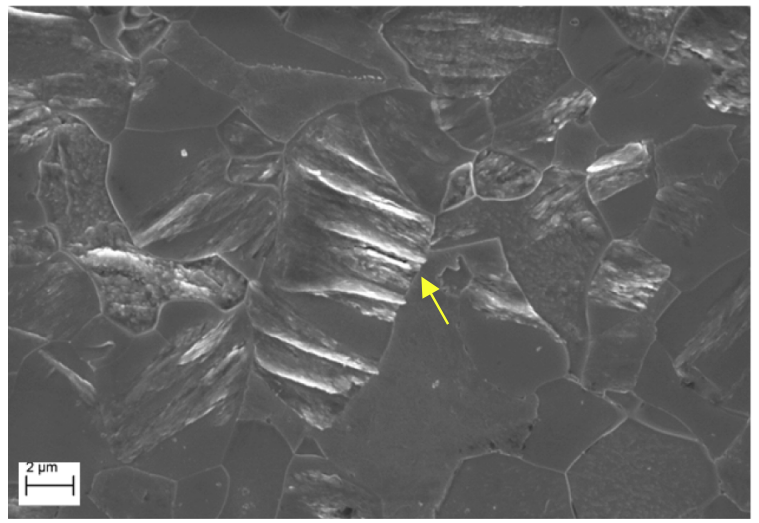

(b)

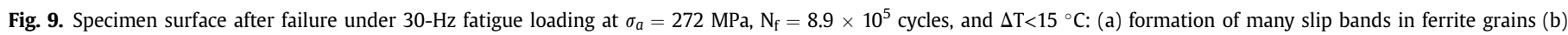
microcrack initiation along slip bands.

behavior. Thus for conventional fatigue tests at room temperature the strain rate is much smaller than the transition strain rate. Therefore, under conventional low frequency fatigue tests, material deformation is expected to occur in athermal regime.

For ultrasonic testing with $20-\mathrm{kHz}$ frequency, the deformation regime depends on stress amplitude because of the presence of strong self-heating discussed in Ref. [23]. For the stress amplitudes below the fatigue limit ( $60 \mathrm{MPa}<\sigma_{a}<260 \mathrm{MPa}$ ), for which no strong heating occurred $\left(\mathrm{T}<40{ }^{\circ} \mathrm{C}\right)$, the maximum strain rate ranges from $36 s^{-1}$ to $156 s^{-1}$. In these high strain rate conditions, the transition temperature ranges from $57{ }^{\circ} \mathrm{C}$ to $74{ }^{\circ} \mathrm{C}$ from Eq. (1), therefore material is expected to deform in thermally-activated mode under ultrasonic loadings at low stress amplitudes. Nonetheless, for ultrasonic loading at higher stress amplitudes (260 $\left.\mathrm{MPa}<\sigma_{a}<305\right) \mathrm{MPa}$, which correspond to the maximum strain rates in the range of $156 \mathrm{~s}^{-1}$ to $182 \mathrm{~s}^{-1}$, the specimen temperature increased to some hundreds of degrees, which is higher than the transition temperature $\left(73^{\circ} \mathrm{C}<T_{0}<76^{\circ} \mathrm{C}\right)$ at the corresponding strain rates so that the material deforms in the athermal regime.

The aforementioned deformation modes under different loading conditions can be confirmed by the SEM observations on the surface of specimens. As depicted in Fig. 5, under ultrasonic loading at low stress amplitudes, no slip band was formed on the specimen surface. On the contrary, ultrasonic loading at high stress amplitudes ( $\left.\sigma_{a}>260 \mathrm{MPa}\right)$ resulted in formation of many slip bands on specimen surface (Fig. 7). Formation of slip bands proves that deformation occurs in the athermal regime. Therefore, it confirms a transition in deformation mode from thermally-activated (at low stress amplitude) to athermal regime (for high stress levels) under ultrasonic fatigue testing. In addition, Fig. 6 shows that under conventional low frequency fatigue tests slip bands were formed in the early stages of cycling even for low stress amplitudes below the fatigue limit and the density of slip bands increased with the number of cycles. Thus, it can be concluded that deformation under low frequency loading occurred in athermal mode for all ranges of stress amplitude. The discussed deformation regimes under each loading condition are summarized in Table 3.

Moreover, comparison of Figs. 8 and 9 reveals that many voids were formed along the slip bands on the surface of ultrasonic specimens, whereas no void was observed on the surface of specimens in the case of conventional fatigue tests. It is know that slip bands produce vacancies which result in formation of tiny voids within the slip bands [33,34]. In the present study, although in both cases (ultrasonic loading at high stress amplitudes and conventional fatigue tests) the DP600 steel deforms in athermal mode leading to formation of slip bands in ferrite grains, ultrasonic loading involves significant temperature increases. At high temperatures such as $350{ }^{\circ} \mathrm{C}$, compared to room temperature, the growth of voids is accelerated by the increase in vacancies amount and their diffusion [34]. In this case voids preferentially form in ferrite grains surrounded by several martensite islands. It could be due to the high amount of localized deformation in these regions which stems from the inhomogeneity between the hard martensite and the soft ferrite phase, as already reported for the case of monotonic tensile loadings of dual-phase steels [35-38].

Nishijima and Kanazawa [39] results suggested that high temperatures induced the formation of an oxide film at the surface of the specimens which restrains the slip deformation at the surface. The dislocations cannot escape through the oxide film and so accumulate in a harder subsurface layer which is also called "debris" layer [40]. This "debris" layer which contains a higher concentration of dislocation promote the generation of vacancies and cavities within slip bands [40,41]. This seems to be in good agreement with the voids observed within the SBs in Fig. 8.

\subsection{Effect of frequency on fatigue life}

As mentioned earlier, the longer fatigue life under ultrasonic loading is usually related to the smaller plastic deformation involved at high frequency due to the higher strain rate $[2,4,6-10]$. However, in our case, as the loading conditions (temperature and strain rate) correspond to the athermal regime, no significant strain rate effect is expected. In the case of dual-phase steel under high temperature cycling, dynamic strain aging is known to occur [23], which results in increasing the yield and tensile strengths of the material. In other words, in spite of the high mobility of screw dislocations in the athermal deformation regime, because of the high temperature, interstitial carbon atoms diffuse around the dislocations and restrict their movements temporarily. It is known that active slip bands are not effectively strengthened by strain aging $[42,43]$. Nevertheless, strain aging strengthens the surrounding ferrite matrix. Consequently, slip bands develop as easily as at room temperature but the plastic zone at the crack tip is smaller and requires higher stresses to propagate. Subsequently, crack propagation in the matrix would be delayed, leading to an increase in the fatigue life for a given stress amplitude. The effect of strain aging on increasing the fatigue life of low-carbon steels at high temperatures have been already reported in the literature $[39,44,45]$. For instance, Nishijima et al. [39] conducted $10-\mathrm{Hz}$ 
Table 3

Deformation regimes under different loading conditions in the present study ( $T_{0}$ is the transition temperature and $\dot{\varepsilon}_{0}$ is the transition strain rate).

\begin{tabular}{lll}
\hline & $\sigma_{a} \leq \sigma_{D}$ & $\sigma_{a}>\sigma_{D}$ \\
\hline Ultrasonic $20-\mathrm{kHz}$ loading & Thermally-activated regime $\left(T<T_{0}\right)$ & Athermal regime $\left(T>T_{0}\right)$ \\
Conventional 30-Hz loading & Athermal regime $\left(\dot{\varepsilon}<\dot{\varepsilon}_{0}\right)$ & Athermal regime $\left(\dot{\varepsilon}<\dot{\varepsilon}_{0}\right)$ \\
\hline
\end{tabular}

fatigue tests on a ferritic-pearlitic steel at high temperatures and showed that the fatigue life and fatigue strength are higher at $300{ }^{\circ} \mathrm{C}$ and $400{ }^{\circ} \mathrm{C}$ compared to the results obtained at room temperature. They attributed this increase in fatigue properties to dynamic strain aging, to which carbon and low-alloy steels are sensitive.

In order to evaluate the effect of temperature and dynamic strain aging on the fatigue life, simple tensile tests were carried out on the material at $350{ }^{\circ} \mathrm{C}$, which corresponds to the high temperature values that the material experienced under ultrasonic fatigue loadings at high stress amplitudes. In this case, the ultimate tensile stress was obtained as $\sigma_{\mathrm{ut}}=740 \mathrm{MPa}$ which is higher than the corresponding value at room temperature, $\sigma_{\mathrm{ut}}=650 \mathrm{MPa}$, as presented in Table 2. Moreover, serrations were observed on the stressstrain curve at $350{ }^{\circ} \mathrm{C}$ which is considered as a criterion for the occurrence of dynamic strain aging [46]. The S-N curves presented in Fig. 2 were replotted by normalizing the stress amplitude by the ultimate tensile strength at room temperature for conventional fatigue test results and by the ultimate tensile strength at $350^{\circ} \mathrm{C}$ for the ultrasonic loading results. The S-N diagrams after normalizing the stress amplitude values are presented in Fig. 10. It should be noted that in this figure run-out samples are not shown as in the case of ultrasonic loading the temperature of the run-out samples remained below $40{ }^{\circ} \mathrm{C}$ and material deformation was in the thermally-activated regime. According to the normalized S-N curve, the stress ratio values for ultrasonic loading are below the corresponding values of conventional low frequency tests. This can explain the higher fatigue life for a given stress amplitude under ultrasonic loading.

\subsection{Effect of frequency on fatigue fracture}

The microscopic observation results presented in Section 3.3 revealed a transgranular crack initiation mode for both ultrasonic and conventional fatigue loadings. In the athermal regime

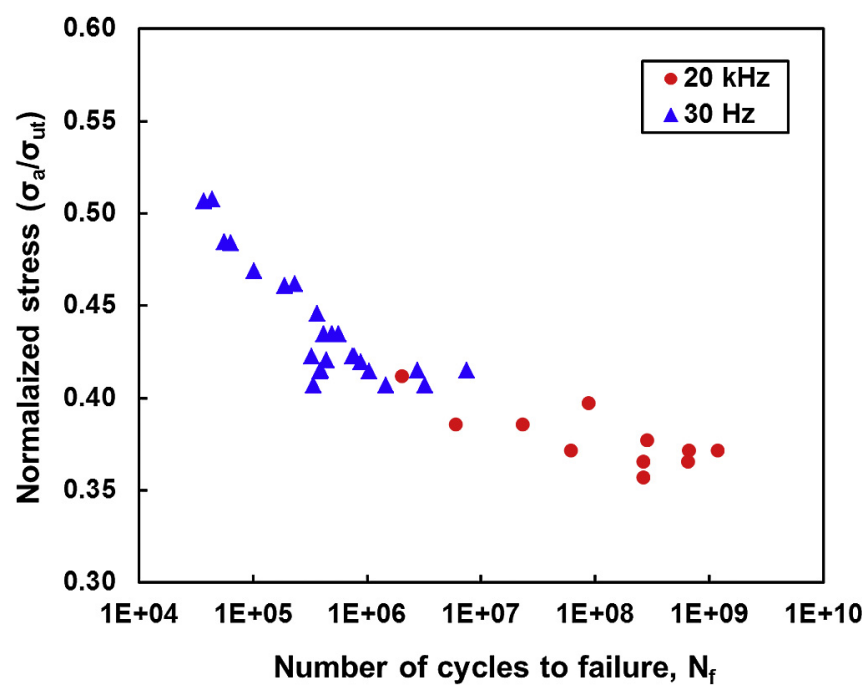

Fig. 10. Assessment of the high temperature effects on the material S-N properties. transgranular crack initiation has been reported to be related to local stress concentration at slip bands while in the thermallyactivated regime intergranular crack initiation is predominant because of stress asymmetry and incompatible deformations at grain boundaries [25,47-49]. It has been reported that for lowcarbon steel, crack initiation mechanism changes from transgranular in conventional fatigue tests to intergranular in ultrasonic loading due to the change in deformation mode from athermal to thermally-activated regime $[10,11]$. In these cases, material deformation mode was athermal under conventional loading while the thermally-activated deformation regime was dominant under ultrasonic fatigue tests. However, for the present DP600 steel, due to strong heating during ultrasonic tests at high stress amplitudes, the deformation regime is athermal, similar to that of conventional low frequency tests. Therefore, in both ultrasonic loadings at high stress amplitudes and conventional low frequency tests, transgranular crack initiation occurs due to local stress concentration at slip bands.

Under conventional fatigue regime $\left(\mathrm{N}<10^{7}\right.$ cycles) fatigue cracks are commonly initiated on the specimen surface due to the irreversible process of extrusions and intrusions within the slip bands [50]. In gigacycle regime, the internal defects play a more important role compared to surface damage specially if the surface is smooth [51]. According to the experimental observations presented in section 3.3, for all the specimens ruptured in gigacycle regime $\left(\mathrm{N}_{\mathrm{f}}>10^{7}\right)$ under ultrasonic loading, fracture was induced by inclusions, even for the few cases of surface fracture initiation. This observation correlates with the findings of Sakai et al. [29] for very high cycle fatigue and the explanation given by Mughrabi [50]: although the fatigue fracture mainly results from the internal inclusions, other types of fracture can occur, including surface fracture initiation when the defects or inclusions are located on the surface.

More specifically, according to Fig. 2, for a given stress amplitude in the range of $264<\sigma_{\mathrm{a}}<300 \mathrm{MPa}$, where the data exist for both loading conditions, fracture was induced by inclusions under ultrasonic loading while for the corresponding fracture cases under conventional loadings there was no inclusion-induced fracture. In addition, Fig. 10 shows that due to strain aging under ultrasonic loading, the stress amplitude normalized by the ultimate tensile stress were below the corresponding values under low frequency tests. The plastic deformation is thus reduced. As mentioned in Section 4.1, the cumulative slip irreversibility at the surface is probably reduced (even if it is enough to form extrusions) because of the material was strengthened by strain aging and/or because of the presence of an oxide layer. In order to assess this hypothesis, more work is needed to measure the height of the extrusion by atomic force microcopy and to discern the presence of an oxide layer. Considering these mechanisms, inclusions, as zones of stress concentration due to metallurgical microstructure misfit, become the sites for initiation and propagation of cracks responsible for failure [52].

\subsection{Correlation of deformation regimes and fatigue fracture}

In order to correlate the fatigue behavior of the material to the strain rate and temperature conditions, a strain rate-temperature 
map associated with deformation mechanisms was developed based on the transition formulation proposed by Rosenfield and Hahn [32] for BCC materials. The developed map is presented in Fig. 11. This map focuses on the transition between athermal regime and thermally-activated regime, which are indicated as Region I and Region II, respectively. The solid line representing the transition boundary between these two deformation regimes was obtained from the empirical equation proposed by Rosenfield and Hahn [32] (see Eq. (1)) for low carbon steels.

The data obtained in the present study for ultrasonic and low frequency fatigue tests of DP600 steel was plotted in this transition map. Moreover, in order to enrich the analysis, the data reported in the literature for DP600 steel as well as several two-phase ferriticpearlitic steels under 20-kHz and low frequency ( $\mathrm{f}<150 \mathrm{~Hz}$ ) fatigue tests was also plotted in this map. The data for DP600 steel were obtained from Munier et al. [53]. The mentioned ferritic-pearlitic steels whose data were extracted from literature are as follows: C15 steel (reported by Bach et al. [25] and by Guennec et al. [10]), C45 steel (Ranc et al. [24] and Bach et al. [25]), and finally Cr-Mo steels (Nishijima \& Kanazawa [39] and Schneider et al. [4]). In addition to these ferritic-pearlitic steels, data reported for Armco iron by Vincent et al. [54] and Wagner et al. [26] was also plotted. Armco iron is single-phase ferrite containing $80 \mathrm{wt} \mathrm{ppm} \mathrm{of} \mathrm{carbon.}$ Studying the pure iron is important since it is the main constituent of ferritic steels which mainly accommodates the deformation and also it can be considered as a model material representing the fatigue characteristics of BCC metals.

It should be noted that concerning the data obtained from the literature, only the information corresponding to longest fatigue life (associated with the lowest stress amplitude) in the reported S$\mathrm{N}$ curves was extracted and plotted in Fig. 11. Table 4 summarizes the experimental information related to all data plotted in Fig. 11, including the material, testing frequency, stress amplitude associated with the longest fatigue life, strain rate amplitude, and specimen temperature. The strain rate amplitude was calculated as $\dot{\varepsilon}_{a}=2 \pi f \frac{\sigma_{a}}{E}$. Concerning the temperature, when self-heating developed during ultrasonic tests, the temperature was considered as the mean temperature before rupture $[23,24,26]$. In the case of low frequency tests, when no temperature information was provided, the tests were considered to be carried out at room temperature, RT $\left(\sim 22{ }^{\circ} \mathrm{C}\right)$ without any self-heating. This case includes the results related to Armco iron in Ref. [54], C15 and C45 steels in Ref. [25], and C15 steel in Ref. [10].

Concerning the largest fatigue life information available in the referenced literature, the data plotted in Fig. 11 can be separated into two regimes:

1. The high cycle fatigue regime ranging from $2 \times 10^{5}$ to $4 \times 10^{7}$ cycles (open symbols and the region denoted by the blue hatch).

2. The very high cycle regime for $\mathrm{N} \geq 2.5 \times 10^{8}$ cycles (full symbols and the region denoted by the red lattice pattern).

The data for HCF failure corresponds to temperatures around RT and are located close to the transition line; The HCF failures under low frequency tests are just below the transition line (Region I) while those under $20 \mathrm{kHz}$ loading are located just above this line (Region II). The difference between these results comes from the sites of microcracks which are located at SBs for plots in Region I
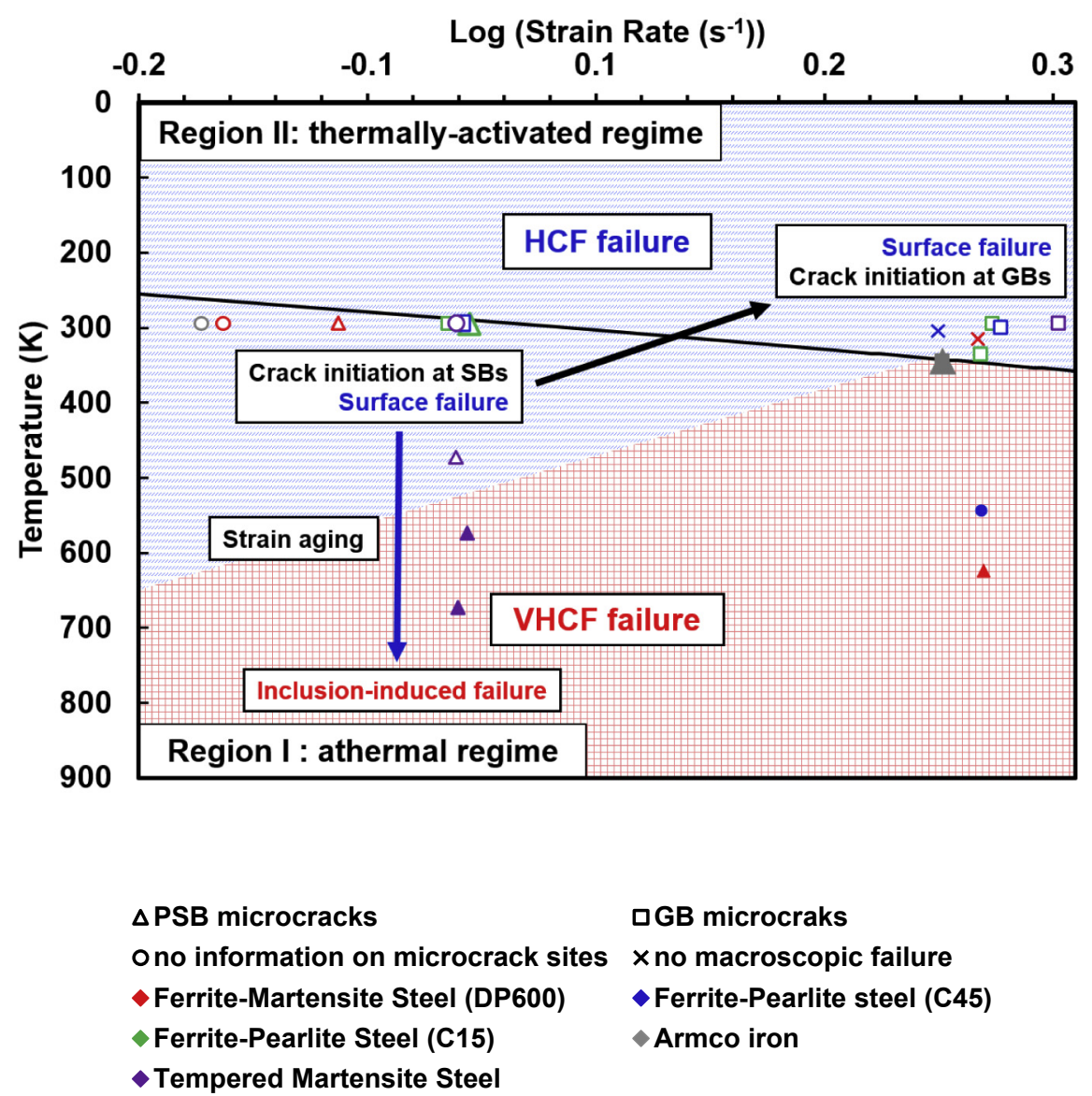

口GB microcraks

$\times$ no macroscopic failure

$\checkmark$ Ferrite-Pearlite steel (C45)

Armco iron

Fig. 11. Regions of the temperature strain-rate spectrum of ferrite base steels that reflect different crack initiation mechanisms and fatigue failure behavior. 
Table 4

Material and experimental properties of the data plotted in Fig. 11.

\begin{tabular}{|c|c|c|c|c|c|c|c|}
\hline Materials & $\begin{array}{l}\text { Frequency } \\
(\mathrm{Hz})\end{array}$ & $\begin{array}{l}\text { Fatigue life } \\
\text { (cycles) }\end{array}$ & $\begin{array}{l}\text { Stress } \\
\text { amplitude (MPa) }\end{array}$ & Strain rate $\left(\mathrm{s}^{-1}\right)$ & Temperature (K) & Reference & Symbol in Fig. 11 \\
\hline DP600 & 30 & $3.2 \times 10^{6}$ & 265 & 0.2 & $295\left(22{ }^{\circ} \mathrm{C}\right)$ & Present work & $\Delta$ \\
\hline DP600 & 20000 & $2.6 \times 10^{8}$ & 265 & 159 & $\sim 623\left(350^{\circ} \mathrm{C}\right)$ & Present work & \\
\hline DP600 & 20000 & Infinite & 240 & 144 & $<313\left(<40^{\circ} \mathrm{C}\right)$ & Torabian et al. [23] & \\
\hline DP600 & 10 & $1.2 \times 10^{6}$ & 250 & 0.07 & $295\left(22{ }^{\circ} \mathrm{C}\right)$ & Munier et al. [53] & \\
\hline 50CrMo4 & $5-400$ & $2 \times 10^{5}$ & 520 & $0.08-6.2$ & $295\left(22^{\circ} \mathrm{C}\right)$ & Schneider et al. [4] & \\
\hline 50CrMo4 & 20000 & $1 \times 10^{6}$ & 560 & 335 & $<333\left(60^{\circ} \mathrm{C}\right)$ & Schneider et al. [4] & \\
\hline 1CrMo0.5 & 100 & $2.6 \times 10^{6}$ & 280 & 0.84 & $295\left(22{ }^{\circ} \mathrm{C}\right)$ & Schneider et al. [4] & \\
\hline 1CrMo0.5 & 100 & $2 \times 10^{6}$ & 260 & 0.78 & $473\left(200^{\circ} \mathrm{C}\right)$ & Nishijima \& Kanazawa [39] & \\
\hline 1CrMo0.5 & 100 & $2.5 \times 10^{8}$ & 290 & 0.87 & $573\left(300{ }^{\circ} \mathrm{C}\right)$ & Nishijima \& Kanazawa [39] & \\
\hline 1CrMo0.5 & 100 & $8 \times 10^{8}$ & 265 & 0.80 & $673\left(400{ }^{\circ} \mathrm{C}\right)$ & Nishijima \& Kanazawa [39] & \\
\hline C45 steel & 20000 & Infinite & 250 & 150 & $305\left(32{ }^{\circ} \mathrm{C}\right)$ & Ranc et al. [24] & \\
\hline C45 steel & 20000 & $4 \times 10^{9}$ & 260 & 156 & $\sim 543\left(270^{\circ} \mathrm{C}\right)$ & Ranc et al. [24] & \\
\hline C45 steel & 20000 & $4 \times 10^{7}$ & 312 & 187 & 300 & Bach et al. [25] & \\
\hline C45 steel & 120 & $1.2 \times 10^{7}$ & 228 & 0.82 & 295 & Bach et al. [25] & \\
\hline C15 steel & 20000 & $1.2 \times 10^{7}$ & 290 & 174 & 295 & Bach et al. [25] & \\
\hline C15 steel & 120 & $1 \times 10^{7}$ & 200 & 0.72 & 295 & Bach et al. [25] & \\
\hline C15 steel & 20000 & $1.4 \times 10^{7}$ & 155 & 135 & 335 & Guennec et al. [10] & \\
\hline C15 steel & 140 & $1.5 \times 10^{6}$ & 210 & 0.88 & 295 & Guennec et al. [10] & $\mu$ \\
\hline Armco iron & 10 & $3 \times 10^{6}$ & 200 & 0.06 & $295\left(22{ }^{\circ} \mathrm{C}\right)$ & Vincent et al. [54] & \\
\hline Armco iron & 20000 & $5 \times 10^{9}$ & 172 & 103 & $345\left(77^{\circ} \in\left[67-87^{\circ} \mathrm{C}\right)\right)$ & Wagner et al. [26] & \\
\hline
\end{tabular}

whereas they are located at grain or phase boundaries for those in Region II. These trends are consistent with the results reported by Sommer et al. [48] for $\alpha$-iron with small carbon content.

In Region I, screw and edge dislocations have similar mobility allowing multiplication and rearrangement of dislocations to localize the deformation in SBs. Fatigue cracks initiate in a transgranular way at these SBs leading to a surface failure mode. On the opposite, in Region II, screw dislocations are much less mobile than edge dislocations preventing SBs from developing. As a result, cracks initiate at the grain and phase boundaries where the strain incompatibilities are the largest. In the thermally activated regime conditions, the plastic deformation is very low but sufficient to produce crack propagation in HCF regime. However, in the VHCF regime failure cannot occur since the stress amplitudes, which are even lower, cannot produce enough plastic deformation for crack propagation and fatigue failure. As shown in Fig. 11, the data points for Armco iron loaded at $20 \mathrm{kHz}$ are very close to the transition line. Interestingly, both transgranular at SBs as well as intergranular cracks were observed for this case [26]. These observations are consistent with the location of the data points in the strain rate-temperature map. Sommer et al. [48] showed that transgranular and intergranular crack initiations are competitive mechanisms depending mainly on the amount of involved plastic strain. Large plastic strain promotes transgranular cracks while small plastic deformation promotes intergranular cracks. In the case of Armco iron under $20 \mathrm{kHz}$ loading, enough plastic deformation occurs to produce failure in the VHCF regime (up to $5 \times 10^{9}$ cycles).

The studied DP600 steel as well as the C45 steel in Ref. [24] loaded in the thermally-activated mode did not exhibit any failure, neither in the HCF nor in the VHCF regime. As expected, no slip band was detected on the surface of the specimens. For C45 steel applying 260-MPa stress amplitude led to a non-avoidable strong self-heating, resulting in a change in strain rate-temperature conditions from the thermally-activated regime to the athermal mode [24]. This change in deformation regime occurred at $\sim \mathrm{N}=8 \times 10^{6}$ cycles, before the failure of the specimen $\left(\mathrm{N}_{\mathrm{f}}=4 \times 10^{7}\right.$ cycles $)$. The results obtained in the present research for DP600 steel can be also explained by the same argument. Specimens loaded at stress amplitudes slightly above $260 \mathrm{MPa}$ exhibited a strong self-heating before reaching failure. As a result, fatigue failure is only possible in the athermal regime.

From these findings, it can be concluded that as soon as the strain rate and temperature conditions under fatigue loading are such that thermally-activated mechanisms are involved, cracks initiate at grain or phase boundaries and result in failure in the HCF regime. No VHCF failure can take place in this case since failure in the VHCF regime involves even lower stresses. Locally at microstructural singularities, crack initiation could take place but in such ductile ferrite-based steels, in thermally-activated regime the mobility of screw dislocations is too low to create multiplication of dislocations and produce enough plastic deformation to cause crack propagation and macroscopic fatigue failure. 
It is striking that the data corresponding to temperatures much higher than RT and typically above $200^{\circ} \mathrm{C}$ belong all to the Region I (athermal regime) and exhibits inclusion-induced VHCF failure. Athermal regime is consistent with the presence of SBs and transgranular microcracks at the surface of the specimens. As mentioned earlier, at these temperatures, carbon steels are sensitive to strain aging. As a result, ferrite is strengthened by solute atoms that segregate in the dislocations leading to impeding their motion. Since the ferrite matrix is strengthened by strain aging the plastic zone at the crack tip is smaller and requires higher stresses to propagate than at temperatures below $200{ }^{\circ} \mathrm{C}$. These higher stress concentrations zone are preferentially found at inclusions because they lead to a higher accumulation of dislocations. This scenario explains why inclusion induced crack initiation were observed for high temperature loadings which is consistent with the discussions presented in Section 4.3. In addition, the increase in fatigue life results from the reduction in plastic deformation at the crack tip and the delay in crack growth in the strengthened ferrite matrix [42], as previously mentioned in Section 4.2.

\subsection{Effect of frequency on fatigue limit}

Based on the experimental observations, for stress amplitudes below the HCF limit determined by $30-\mathrm{Hz}$ fatigue tests, slip bands and microcracks were also visible on the surface of the run-out specimens. These observations demonstrated that the $260 \mathrm{MPa}$ HCF fatigue limit is not related to slip activity and microcrack initiation. Moreover, in the case of $20-\mathrm{kHz}$ loading no slip band was detected on the surface of run-out samples. It is well supported in the literature that the fatigue limit of steels corresponds to a slightly higher stress level at which an initiated microcrack stops propagating at the first microstructural barrier [29,39,55]. In other words, the fatigue limit is related to the stress threshold required to propagate the trapped microcracks. Therefore, on the one hand, based on the previously mentioned strain aging effects in strengthening the ferrite matrix, it is expected that the fatigue limit is higher under ultrasonic loading. On the other hand, at high temperatures, such as $350{ }^{\circ} \mathrm{C}$ compared to room temperature, the vacancy diffusion along the slip band is higher, leading to accelerating the voids growth. The presence of voids in the vicinity of inclusions could decrease the cohesion strength of the material to a point where crack propagation begins [56]. Consequently, microcracks propagate more easily at high than low temperatures leading to decreasing the fatigue limit normalized by the ultimate tensile strength. These competitive mechanisms finally led to the same absolute fatigue limit in ultrasonic loading and conventional tests. However further investigations are required to confirm this hypothesis which is the subject of the future work of the authors.

To summarize, in the present case of the DP600 steels loaded using continuous cycling at $30 \mathrm{~Hz}$ and $20 \mathrm{kHz}$, fatigue failure was observed only for strain rate-temperature conditions implying athermal deformation mechanisms. Therefore, comparable screw and edge dislocation mobility constituted a necessary condition for fatigue failure. At $30 \mathrm{~Hz}$, this condition is immediately satisfied and the fatigue limit is associated with the stress threshold requires to propagate cracks. This threshold was found $\sim 260 \mathrm{MPa}$. At $20 \mathrm{kHz}$, the fatigue limit of $260 \mathrm{MPa}$ corresponds to the critical stress amplitude $\sigma_{c}$, necessary to produce enough dissipated energy to get a self-heating above $\sim 75^{\circ} \mathrm{C}$. The origin of these two fatigue limits seems thus to be different. However, the fact that the fatigue limits are the same suggests that the self-heating above $75^{\circ} \mathrm{C}$, could be also related to crack propagation; short cracks could be formed but stopped because of the strain aging strengthening, as previously mentioned in Ref. [23]. Thus $\sigma_{c}$ could be also the threshold stress required to crack propagation which is consistent with the definition of fatigue limit.

\section{Conclusions}

The effect of frequency on fatigue behavior of ferriticmartensitic dual-phase steel was studied by carrying out ultrasonic and conventional low frequency tension-compression fatigue tests along with temperature measurements and microscopic observations. A clear discrepancy was observed in the S-N curves obtained from conventional $30-\mathrm{Hz}$ fatigue tests and that measured from ultrasonic $20-\mathrm{kHz}$ loadings. The rate- and temperaturedependent flow behavior of the ferrite phase, as a BCC structure, was found to be a decisive parameter explaining the effects of frequency on fatigue and thermal response of the material. Moreover, the significant temperature increase under ultrasonic fatigue loading at high stress amplitudes was found to play an important role in the observed phenomena. The principal conclusions drawn from the results of this study can be summarized as follows:

- Under ultrasonic fatigue loading, there was a transition in material deformation mode from thermally-activated regime at stress amplitudes below the fatigue limit to athermal mode at stress amplitudes above the fatigue limit. Nonetheless, material deformation occurred in athermal regime under conventional low frequency fatigue tests for all stress amplitude ranges.

- The higher fatigue life was attributed to the dynamic strain aging which resulted from the high temperature increases at high stress amplitudes. However, the same fatigue limits remain as an open question to be investigated in a future work, even if some insights were proposed

- In both ultrasonic and low frequency tests transgranular cracking along the slip bands was observed and no intergranular crack was detected. In the case of ultrasonic loading, many microvoids nucleated and coalesced along the slip bands resulting in microcrack initiations. This microvoids initiations and coalescences were not observed in the case of low frequency tests. Diffusion of vacancies due to high temperature under ultrasonic fatigue loading is thought to be the main cause of microvoids formation.

- Surface fracture initiation from slip bands was observed in low and high cycle regimes under conventional tests, while under ultrasonic loading fracture initiation was always inclusioninduced.

- The S-N curves were replotted by normalizing the stress amplitudes by the ultimate tensile strengths at corresponding loading temperatures in order to consider the effect of dynamic strain aging for ultrasonic loading. This replotting rationalized the S-N data, resulting in lower stress ratios for ultrasonic loading, which can explain the higher fatigue life and inclusioninduced crack initiations under $20-\mathrm{kHz}$ ultrasonic tests.

- A strain rate-temperature transition map was developed based on the experimental findings for DP600 steel and the data reported in the literature for several ferrite based steels. It was shown that no VHCF failure occurs if material deforms in thermally-activated regime and in that condition, microcracks initiated at grain or phase boundaries for HCF failure. VCHF fatigue failure was observed only for strain rate-temperature conditions implying athermal deformation mechanisms associated with microcracks within slip bands.

\section{Acknowledgement}

The authors would like to acknowledge Mr. Bastien Weber from ArcelorMittal Maizières Research \& Development, for providing the material and for fruitful discussions. 


\section{References}

[1] R. Ebara, The present situation and future problems in ultrasonic fatigue testing mainly reviewed on environmental effects and materials' screening, Int. J. Fatigue 28 (2006) 1465-1470, http://dx.doi.org/10.1016/j.ijfatigue.2005.04.019.

[2] H. Mayer, Recent developments in ultrasonic fatigue, Fatigue Fract. Eng. Mater. Struct. 39 (2016) 3-29, http://dx.doi.org/10.1111/ffe.12365.

[3] B. Holper, H. Mayer, A.K. Vasudevan, S.E. Stanzl-Tschegg, Near threshold fatigue crack growth in aluminium alloys at low and ultrasonic frequency: influences of specimen thickness, strain rate, slip behaviour and air humidity, Int. J. Fatigue 25 (2003) 397-411, http://dx.doi.org/10.1016/S0142-1123(02) 00163-9.

[4] N. Schneider, J. Boddecker, C. Berger, M. Oechsner, Frequency effect and influence of testing technique on the fatigue behaviour of quenched and tempered steel and aluminium alloy, Int. J. Fatigue 93 (2016) 224-231, http:/ dx.doi.org/10.1016/j.ijfatigue.2016.05.013.

[5] S. Stanzl-Tschegg, Very high cycle fatigue measuring techniques, Int. J. Fatigue 60 (2014) 2-17, http://dx.doi.org/10.1016/j.ijfatigue.2012.11.016.

[6] N. Tsutsumi, Y. Murakami, V. Doquet, Effect of test frequency on fatigue strength of low carbon steel, Fatigue Fract. Eng. Mater. Struct. 32 (2009) 473-483, http://dx.doi.org/10.1111/j.1460-2695.2009.01350.x.

[7] I. Nonaka, S. Setowaki, Y. Ichikawa, Effect of load frequency on high cycle fatigue strength of bullet train axle steel, Int. J. Fatigue 60 (2014) 43-47, http://dx.doi.org/10.1016/j.ijfatigue.2013.08.020.

[8] H.Q. Liu, Q.Y. Wang, Z.Y. Huang, Z.J. Teng, High-cycle fatigue and thermal dissipation investigations for low carbon steel Q345, Key Eng. Mater. 664 (2015) 305-313, http://dx.doi.org/10.4028/www.scientific.net/KEM.664.305.

[9] B. Guennec, A. Ueno, T. Sakai, M. Takanashi, Y. Itabashi, Effect of the loading frequency on fatigue properties of JIS S15C low carbon steel and some discussions based on micro-plasticity behavior, Int. J. Fatigue 66 (2014) 29-38, http://dx.doi.org/10.1016/j.ijfatigue.2014.03.005.

[10] B. Guennec, A. Ueno, T. Sakai, M. Takanashi, Y. Itabashi, M. Ota, Dislocationbased interpretation on the effect of the loading frequency on the fatigue properties of JIS S15C low carbon steel, Int. J. Fatigue 70 (2015) 328-341, http://dx.doi.org/10.1016/j.ijfatigue.2014.10.006.

[11] Y. Furuya, S. Torizuka, E. Takeuchi, M. Bacher-Höchst, M. Kuntz, Ultrasonic fatigue testing on notched and smooth specimens of ultrafine-grained steel, Mater. Des. 37 (2012) 515-520, http://dx.doi.org/10.1016/j.matdes.2012.01.035.

[12] A. Seeger. The temperature dependence of the criticla shear stress and of work-hardening of metal crystals, Philos. Mag. Ser. 7 (45) (1954) 771-773, http://dx.doi.org/10.1080/14786440708520489.

[13] H. Mughrabi, K. Herz, X. Stark, Cyclic deformation and fatigue behaviour of alpha-iron mono-and polycrystals, Int. J. Fract. 17 (1981) 193-220, http:/ dx.doi.org/10.1007/BF00053520.

[14] C. Bathias, Coupling effect of plasticity, thermal dissipation and metallurgical stability in ultrasonic fatigue, Int. J. Fatigue 60 (2014) 18-22, http:/ dx.doi.org/10.1016/j.ijfatigue.2013.06.004.

[15] S. Schmid, M. Hahn, S. Issler, M. Bacher-Hoechst, Y. Furuya, A. Mehner H. Bomas, H.W. Zoch, Effect of frequency and biofuel E85 on very high cycle fatigue behaviour of the high strength steel X90CrMoV18, Int. J. Fatigue 60 (2014) 90-100, http://dx.doi.org/10.1016/j.ijfatigue.2013.06.005.

[16] Y. Furuya, S. Matsuoka, T. Abe, K. Yamaguchi, Gigacycle fatigue properties for high-strength low-alloy steel at $100 \mathrm{~Hz}, 600 \mathrm{~Hz}$, and $20 \mathrm{kHz}$, Scr. Mater 46 (2002) 157-162, http://dx.doi.org/10.1016/S1359-6462(01)01213-1.

[17] I. Marines, G. Dominguez, G. Baudry, J.F. Vittori, S. Rathery, J.P. Doucet, C. Bathias, Ultrasonic fatigue tests on bearing steel AISI-SAE 52100 at frequency of 20 and $30 \mathrm{kHz}$, Int. J. Fatigue 25 (2003) 1037-1046, http:/ dx.doi.org/10.1016/S0142-1123(03)00161-0.

[18] Q.Y. Wang, J.Y. Berard, A. Dubarre, G. Baudry, S. Rathery, C. Bathias, Gigacycle fatigue of ferrous alloys, Fatigue Fract. Eng. Mater. Struct. 22 (1999) 667-672, http://dx.doi.org/10.1046/j.1460-2695.1999.00185.x.

[19] N. Ranc, D. Wagner, P.C. Paris, Study of thermal effects associated with crack propagation during very high cycle fatigue tests, Acta Mater 56 (2008) 4012-4021, http://dx.doi.org/10.1016/j.actamat.2008.04.023.

[20] Y. Yu, J.L. Gu, L. Xu, F.L. Shou, B.Z. Bai, Y.B. Liu, Very high cycle fatigue behaviors of Mn-Si-Cr series Bainite/Martensite dual phase steels, Mater. Des. 31 (2010) 3067-3072, http://dx.doi.org/10.1016/j.matdes.2010.01.008.

[21] W.J. Peng, B.W. Qiu, R.F. Li, H. Xue, Ultrasonic fatigue tests on a high strength steel for welded structure, Adv. Mater. Res. 503-504 (2012) 714-717, http:// dx.doi.org/10.4028/www.scientific.net/AMR.503-504.714.

[22] W. Peng, Y. Zhang, B. Qiu, H. Xue, A brief review of the application and problems in ultrasonic fatigue testing, AASRI Procedia 2 (2012) 127-133, http://dx.doi.org/10.1016/j.aasri.2012.09.024.

[23] N. Torabian, V. Favier, S. Ziaei-Rad, J. Dirrenberger, F. Adamski, N. Ranc, Therma response of DP600 dual-phase steel under ultrasonic fatigue loading, Mater. Sci. Eng. A 677 (2016) 97-105, http://dx.doi.org/10.1016/j.msea.2016.09.025.

[24] N. Ranc, V. Favier, B. Munier, F. Vales, G. Thoquenne, F. Lefebvre, Therma response of C45 steel in high and very high cycle fatigue, Procedia Eng. 133 (2015) 265-271, http://dx.doi.org/10.1016/j.proeng.2015.12.668.

[25] J. Bach, J.J. Möller, M. Göken, E. Bitzek, H.W. Höppel, On the transition from plastic deformation to crack initiation in the high- and very high-cycle fatigue regimes in plain carbon steels, Int. J. Fatigue 93 (2016) 281-291, http:// dx.doi.org/10.1016/j.ijfatigue.2016.04.003.
[26] D. Wagner, C. Wang, Z. Huang, C. Bathias, Surface crack initiation mechanism for body centered cubic materials in the gigacycle fatigue domain, Int. J. Fatigue 93 (2016) 292-300, http://dx.doi.org/10.1016/j.ijfatigue.2016.05.036.

[27] N. Marti, V. Favier, N. Saintier, F. Gregori, Investigating fatigue frequency effects on single phase ductile materials, Procedia Eng. 133 (2015) 294-298, http://dx.doi.org/10.1016/j.proeng.2015.12.675.

[28] R. Munier, C. Doudard, S. Calloch, B. Weber, Determination of high cycle fatigue properties of a wide range of steel sheet grades from self-heating measurements, Int. J. Fatigue 63 (2014) 46-61, http://dx.doi.org/10.1016/ j.ijfatigue.2014.01.004

[29] T. Sakai, A. Nakagawa, N. Oguma, Y. Nakamura, A. Ueno, S. Kikuchi, A. Sakaida, A review on fatigue fracture modes of structural metallic materials in very high cycle regime, Int. J. Fatigue (2016) 1-13, http://dx.doi.org/10.1016/ j.ijfatigue.2016.05.029.

[30] C.R. Sohar, A. Betzwar-Kotas, C. Gierl, B. Weiss, H. Danninger, Gigacycle fatigue behavior of a high chromium alloyed cold work tool steel, Int. J. Fatigue 30 (2008) 1137-1149, http://dx.doi.org/10.1016/j.ijfatigue.2007.09.012.

[31] P.J.E. Forsyth, Fatigue damage and crack growth in aluminium alloys, Acta Metall. 11 (1963) 703-715, http://dx.doi.org/10.1016/0001-6160(63)900087.

[32] A.R. Rosenfield, G.T. Hahn, Numerical descriptions of the ambient lowtemperature and high-strain rate flow and fracture behavior of plain carbon steel, Trans. Am. Soc. Mater 59 (1966) 962-977.

[33] U. Essmann, U. Gösele, H. Mughrabi, A model of extrusions and intrusions in fatigued metals I. Point-defect production and the growth of extrusions, Philos. Mag. A 44 (1981) 405-426, http://dx.doi.org/10.1080/01418618108239541.

[34] J. Polák, M. Sauzay, Growth of extrusions in localized cyclic plastic straining, Mater. Sci. Eng. A 500 (2009) 122-129, http://dx.doi.org/10.1016/j.msea.2008.09.022.

[35] J.H. Kim, M.G. Lee, D. Kim, D.K. Matlock, R.H. Wagoner, Hole-expansion formability of dual-phase steels using representative volume element approach with boundary-smoothing technique, Mater. Sci. Eng. A 527 (2010) 7353-7363, http://dx.doi.org/10.1016/j.msea.2010.07.099.

[36] A. Alaie, J. Kadkhodapour, S. Ziaei Rad, M. Asadi Asadabad, S. Schmauder, Formation and coalescence of strain localized regions in ferrite phase of DP600 steels under uniaxial tensile deformation, Mater. Sci. Eng. A 623 (2015) 133-144, http://dx.doi.org/10.1016/j.msea.2014.11.042.

[37] Q. Lai, O. Bouaziz, M. Gouné, L. Brassart, M. Verdier, G. Parry, A. Perlade, Y. Bréchet, T. Pardoen, Damage and fracture of dual-phase steels: in fluence of martensite volume fraction, Mater. Sci. Eng. A 646 (2015) 322-331, http:// dx.doi.org/10.1016/j.msea.2015.08.073.

[38] A. Pierman, O. Bouaziz, T. Pardoen, PJ. Jacques, L. Brassart, ScienceDirect the influence of microstructure and composition on the plastic behaviour of dualphase steels, Acta Mater 73 (2014) 298-311, http://dx.doi.org/10.1016/ j.actamat.2014.04.015.

[39] S. Nishijima, K. Kanazawa, Stepwise S-N curve and fish-eye failure in gigacycle fatigue, Fatigue Fract. Eng. Mater. Struct. 22 (1999) 601-607, http:// dx.doi.org/10.1046/j.1460-2695.1999.00206.x.

[40] H. Shen, S.E. Podlaseck, I.R. Kramer, Effect of vacuum on the fatigue life of aluminum, Acta Metall. 14 (1966) 341-346.

[41] W.A. Wood, K.R. Sargant, Systematic microstructural changes peculiar to fatigue deformation, Acta Metall. 11 (1963) 643-652.

[42] D.V. Wilson, J.K. Tromans, Effects of strain ageing on fatigue in low-carbon steel, Acta Metall. 18 (1970) 1197-1208.

[43] K. V Jata, E.A. Starke, fatigue crack growth and fracture toughness behavior of an AI-Li-Cu alloy, Metall. Trans. A 17 (1986) 1011-1026.

[44] K. Pohl, P. Mayr, E. Macherauch, Cyclic deformation behavior of a low carbon steel in the temperature range between room temperature and $850 \mathrm{~K}$, Int. J. Fract. 17 (1981) 221-233, http://dx.doi.org/10.1007/BF00053521.

[45] N. Thompson, N.J. Wadsworth, Metal fatigue, Adv. Phys. 7 (1958) 72-169, http://dx.doi.org/10.1080/00018735800101177.

[46] G. Schoeck, The portevin-le chatelier effect. A kinetic theory, Acta Metall. 32 (1984) 1229-1234, http://dx.doi.org/10.1016/0001-6160(84)90129-9.

[47] T. Magnin, J.H. Driver, The influence of strain rate on the low cycle fatigue properties of single crystals and polycrystals of two ferritic alloys, Mater. Sci. Eng. 39 (1979) 175-185, http://dx.doi.org/10.1016/0025-5416(79)90057-0.

[48] C. Sommer, H. Mughrabi, D. Lochner, Influence of temperature and carbon content on the cyclic deformation and fatigue behaviour of $\alpha$-iron. Part I. Cyclic deformation and stress-behaviour, Acta Mater 46 (1998) 1527-1536, http://dx.doi.org/10.1016/S1359-6454(97)00362-5.

[49] C. Sommer, H. Mughrabi, D. Lochner, Influence of temperature and carbon content on the cyclic deformation and fatigue behaviour of $\alpha$-iron. Part II: crack initiation and fatigue life, Acta Mater 46 (1998) 1537-1546, http:// dx.doi.org/10.1016/S1359-6454(97)00363-7.

[50] H. Mughrabi, Specific features and mechanisms of fatigue in the ultrahighcycle regime, Int. J. Fatigue 28 (2006) 1501-1508, http://dx.doi.org/10.1016/ j.ijfatigue.2005.05.018.

[51] C. Bathias, There is no infinite fatigue life in metallic materials, Fatigue Fract. Eng. Mater. Struct. 22 (1999) 559-565, http://dx.doi.org/10.1046/j.14602695.1999.00183.x

[52] K. Tanaka, T. Mura, A dislocation model for fatigue crack initiation, J. Appl. Mech. 48 (1981) 97-103, http://dx.doi.org/10.1115/1.3157599.

[53] R. Munier, C. Doudard, S. Calloch, B. Weber, Towards a faster determination of high cycle fatigue properties taking into account the influence of a plastic pre- 
strain from selfheating measurements, Procedia Eng. 2 (2010) 1741-1750, http://dx.doi.org/10.1016/j.proeng.2010.03.187.

[54] M. Vincent, Y. Nadot, A. Dragon, Interaction between a surface defect and grain size under high cycle fatigue loading: experimental approach for Armco iron, Int. J. Fatigue 87 (2016) 81-90, http://dx.doi.org/10.1016/j.ijfatigue.2016.01.013.

[55] G. Meneghetti, Analysis of the fatigue strength of a stainless steel based on the energy dissipation, Int. J. Fatigue 29 (2007) 81-94, http://dx.doi.org/10.1016/ j.ijfatigue.2006.02.043.

[56] G.M. Sinclair, C.E. Feltner, Fatigue strength of crystalline solids, in: American Society for Testing Materials, 1961, pp. 129-142. Spec. Tech. Publ. no. 283, Piladelphia. 